\title{
Multi-piece post-crown for multi-rooted teeth with non-parallel canals: a direct pattern technique
}

\begin{abstract}
Problems associated with custom cast posts for multi-rooted teeth with nonparallel canals following the traditional direct pattern technique result from using different metals in fabricating post core systems include failures due to electrolytic action of dissimilar metals and unfavorable effect upon the physical properties of wrought metal posts. The preheating temperature of the investment mold may lead to recrystalization of the wrought metal post. This article describes a technique, for constructing custom-cast post-core system for the multirooted teeth with nonparallel canals, to address these problems. The technique is simple, accurate, reproducible, and eliminates the drawbacks of the traditional direct postcore pattern for multirooted teeth with non-parallel canals.
\end{abstract}

Keywords: direct pattern materials, multisectional custom cast post materials, multi rooted teeth with non parallel canals
Volume I Issue 4 - 2014

\author{
Nagy Abdul Samee Abdul Hameed \\ Dental Biomaterials, College of Oral and Dental Medicine, Misr \\ University for Science \& Technology, Egypt
}
Correspondence: Nagy Abdul-Samee Abdul-Hameed, Dental Biomaterials, College of Oral and Dental Medicine, Misr
University for Science \& Technology, Al-Motamayez District, P.O. Box: 77, 6th of October City, Egypt, Tel 201007920780, Email nagyabdulsamee@yahoo.com

Received: August 06, 2014 | Published: September 22, 2014

\section{Introduction}

Adequate restorations must be done to the endodontically treated teeth because these teeth are considered brittle and remaining coronal tooth structure is mostly inadequate to retain full crowns. ${ }^{1}$ The procedures traditionally involve posts and core followed by full crowns. The development of cast dowel cores was a logical evolution from the Richmond crown. Custom cast post and cores are well suited for canals that have an extremely tapered, noncircular cross section, irregularly shaped canals, and roots with little or no coronal tooth structure remaining. ${ }^{2,3}$

The multi-piece post-crown technique is more effective in restoring residual root than other restoration techniques. ${ }^{4}$ The direct pattern can be used for multi-rooted posterior teeth, with non-parallel canals, although limited access may make the indirect approach easier. The indirect technique has many drawbacks that may affect the accuracy and retention of the post. It needs extra steps like taking an impression and pouring a die, and air bubbles may be incorporated into post-hole spaces making removal of the wax patterns impossible.

The conventional direct pattern technique involves fitting prefabricated posts into prepared post holes, one post is roughened and the others are left smooth and lubricated. All posts should extend beyond the eventual preparation. The core is built up with coldcure resin and shaped after hardening to the final form. The smooth lubricated posts are gripped with forceps and removed leaving holes in their place through the core. Resin pattern of the core with the roughened single post is invested and cast. The holes for the auxiliary posts can be refined with twist drill. After try in, the core is cemented and excess cement is removed from auxiliary post holes with twist drill, and the auxiliary posts are cemented to place.

A major drawback of the traditional direct pattern technique is related to using potentially corrodible dissimilar metals for post and core. Many researchers concluded that there is a correlation between root fracture and corrosion of the base metal prefabricated post and cast core systems restoring them..$^{5-8}$ One study, reporting on 468 teeth with vertical or oblique root fracture, attributed $72 \%$ of these failures to electrolytic action of dissimilar metals used for the post and core. The mechanism was postulated as the corrosion products caused a volume change that split the root. ${ }^{5}$ Another drawback results from casting a core onto a prefabricated post system is that the casting process may unfavorably affect the physical properties of wrought metal posts. The preheating temperature of the investment mold may lead to recrystalization of the wrought metal post. ${ }^{9}$

In an attempt to overcome the drawbacks of the traditional direct pattern technique for multi-rooted teeth with non-parallel canals, this article described a technique for rapidly constructing direct pattern for posts and their corresponding core sections and hence can be cast from the same alloy.

\section{Materials and methods}

a. Prepare post hole spaces following the standard procedures. Rotary instruments (Penetration drill of Unimetric Set, Dentsply, Switzerland) were used to remove gutta-percha to prepare post hole spaces. Chemical solvents were not used to remove gutta percha to avoid apical leakage. ${ }^{10,11}$

b. Roughen loose-fitting orthodontic wires $(0.7 \mathrm{~mm}$ in diameter, Stainless Steel wire, Dentoform, USA) was tried into the prepared post spaces (Figure 1 and 2). They should extend to the prepared canals full depth.

c. Lightly lubricate one canal with a periodontal probe and petroleum jelly (Relience Dental Manufacturing Co) and temporarily block other post hole or holes with cotton.

d. A cold cure resin, such Durallay (Relience Dental Manufacturing Co) is mixed to a low-viscosity consistency and is loaded into a needle tube that is inserted into a Mark IIIp Speed Slot syringe (Centrix). The acrylic resin is injected into the canal beginning at the apical end of the canal and 
moving incisally as the resin is extruded from the syringe The fitted orthodontic wire is wetted with the monomer liquid and inserted into the acrylic resin in the canal. The remaining acrylic resin in the needle tube is extruded from the syringe to form the core portion of the pattern. The resin pattern is loosened and reseated several times while it is still elastic but not removed entirely from the canal. ${ }^{12-14}$

e. Once the resin has polymerized, remove the pattern and inspect for any defects or voids. Correct defects any voids by adding resin or soft wax and reseat the post. The core section is modified by removing any undercut adjacent to the other post-holes and to make dovetails grooves and lubricate it with petroleum jelly. Keep this post with its section of the core in place inside the tooth and build up the other post or posts with their corresponding section of the core, following steps 3 through 5 for the other canal or canals using either hard inlay pattern $\operatorname{wax}^{15}$ (Keystone, USA), cold-cure resin (Durallay) (Figure 3 and 4), light-cured rein, ${ }^{16}$ or thermoplastic resin. ${ }^{17}$

f. Invest post-core patterns (Figure 5) and cast those following standard techniques (no asbestos substitute liner).

g. Divest them and finish (Figure 6), and try them into the prepared canals (Figure 7 and 8), then cement them.

h. A clinical case for restoring endotreated tooth \#36 with casted post core by the same technique mentioned in steps 1 through 7 is shown in (Figures 9-13)

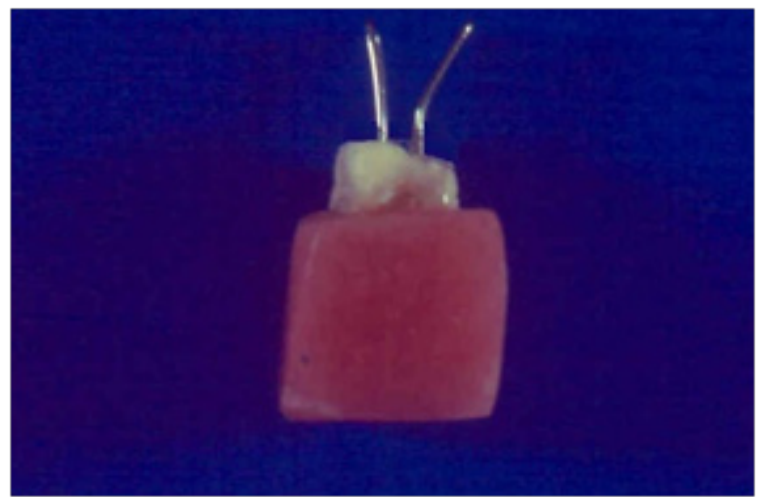

Figure I Roughened loose-fitting orthodontic wires in the prepared post spaces.

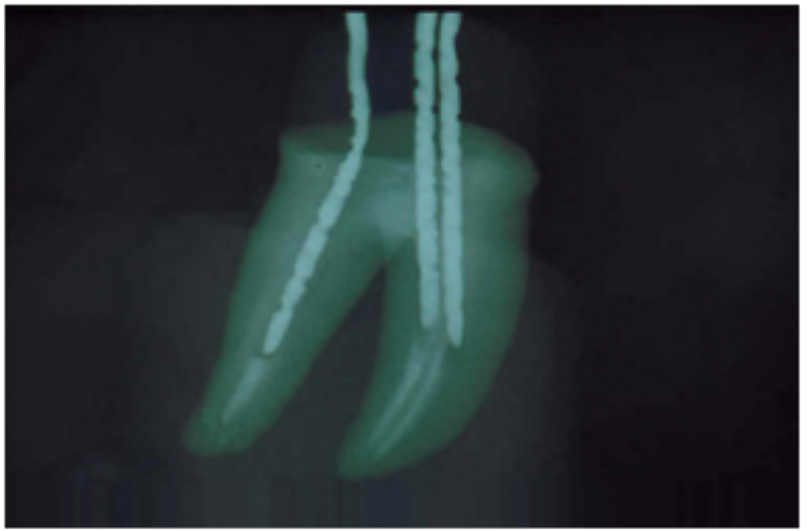

Figure $2 \mathrm{X}$-ray shows the wires extend into the full depth of the prepared canals.

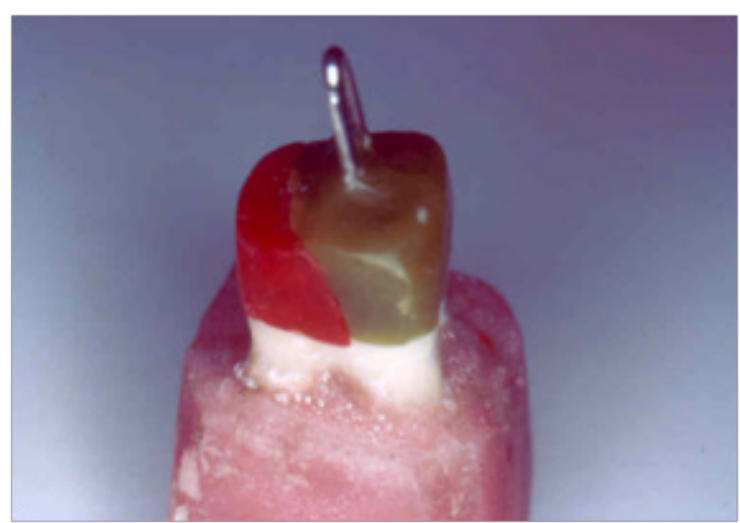

Figure 3 Finished post core pattern sections in place on the tooth.

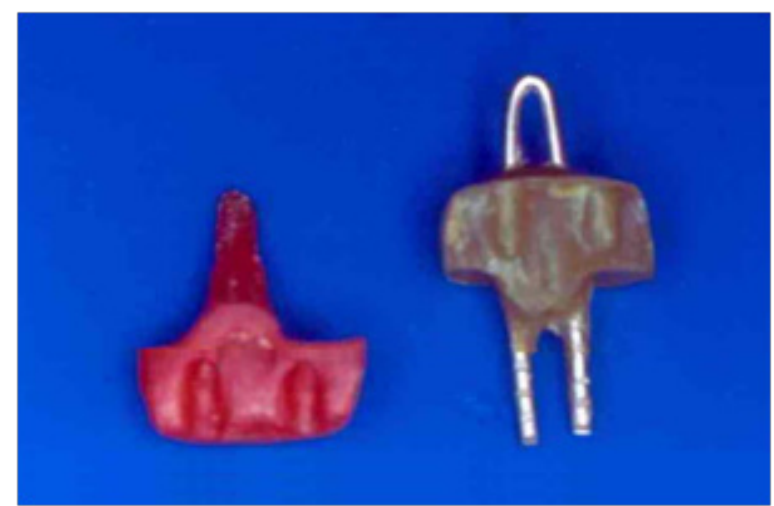

Figure 4 Finished post core sections removed from the tooth and ready for investing.

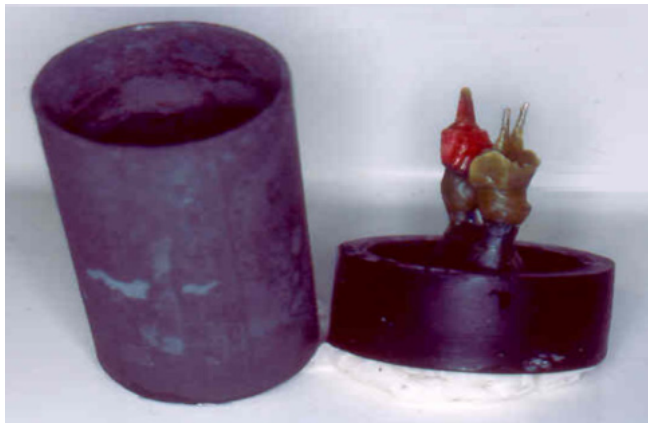

Figure 5 Post core sections attached to sprues for investing (Note that the ring is not lined with asbestos substitute).

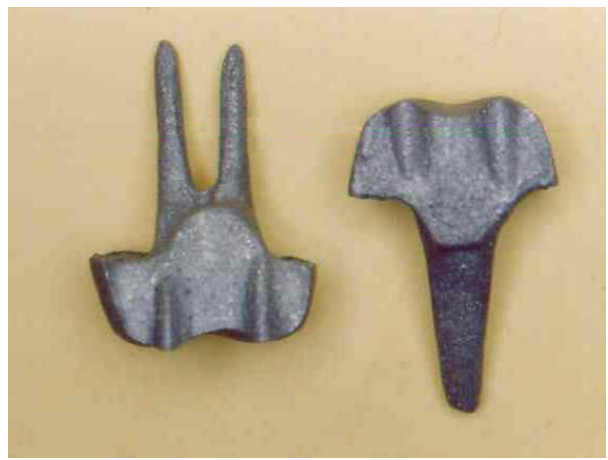

Figure 6 Cast post core sections. 


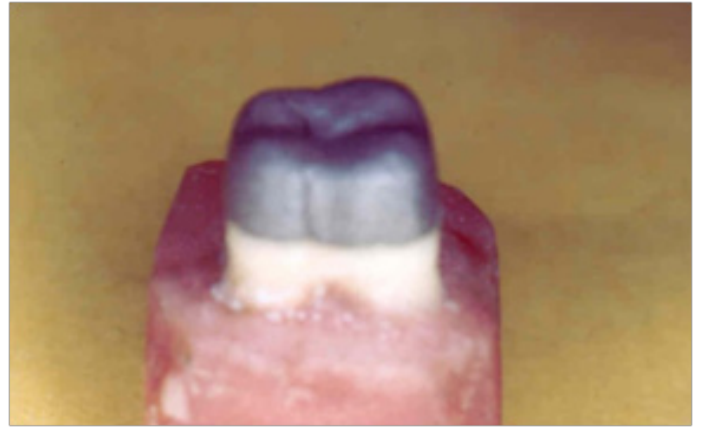

Figure 7 Completed cast post core sections in their place post core onto the prepared tooth.

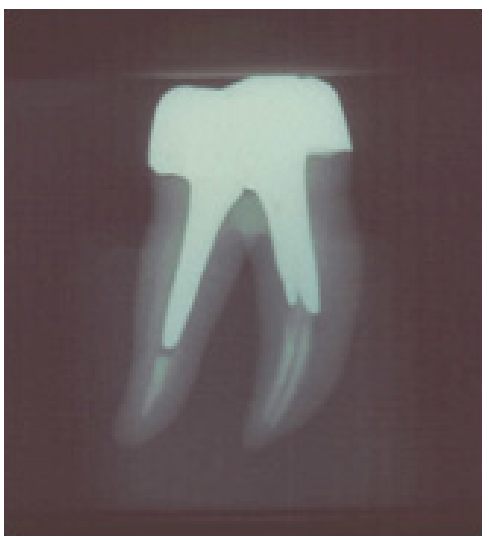

Figure 8 X-ray of the completed cast sections in their place.

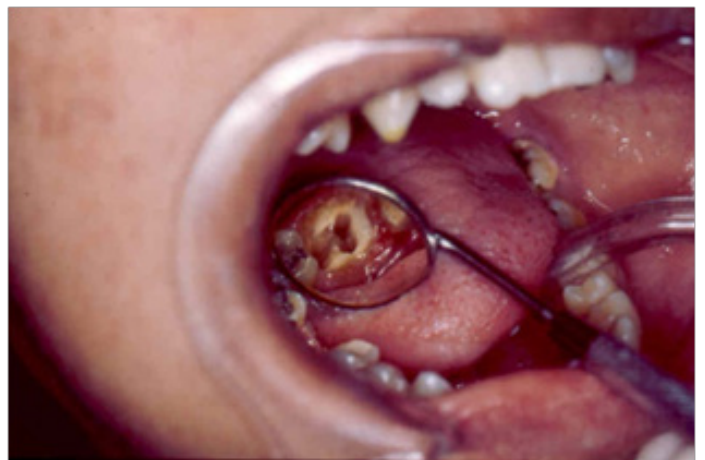

Figure 9 Tooth \# 36 with prepared post holes.

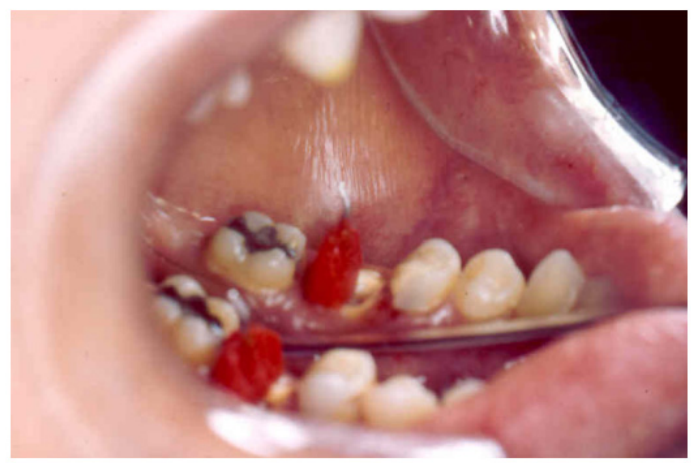

Figure 10 Duralay post pattern of the distal canal with section of the core.

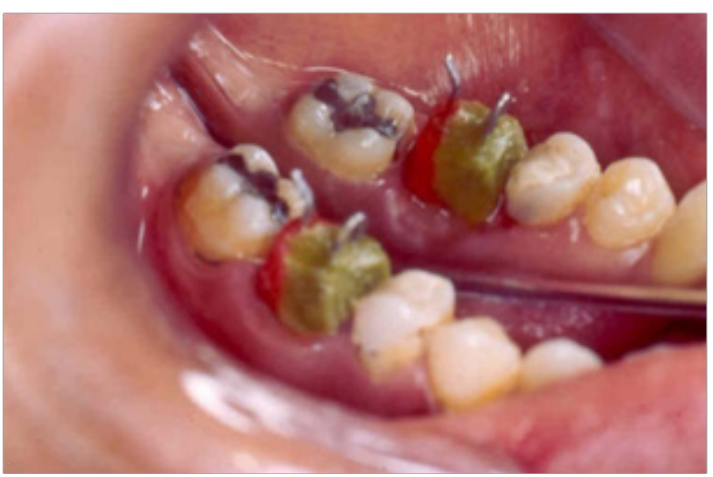

Figure I I Inlay pattern wax post pattern of the mesial canals with the remaining section of the core.

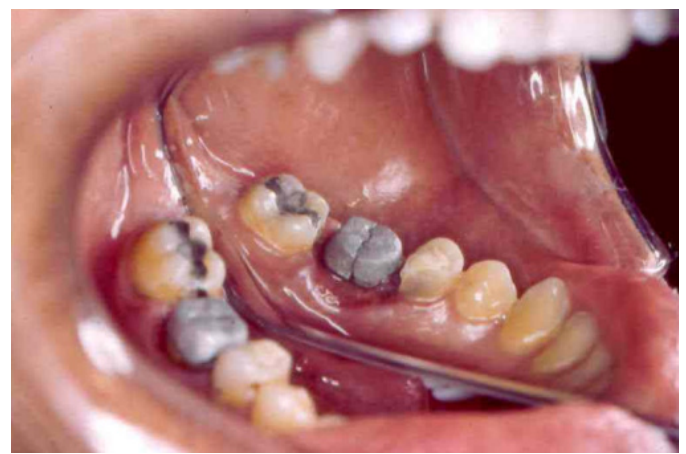

Figure I 2 Try in of the finished cast multi sectional post \& Core.

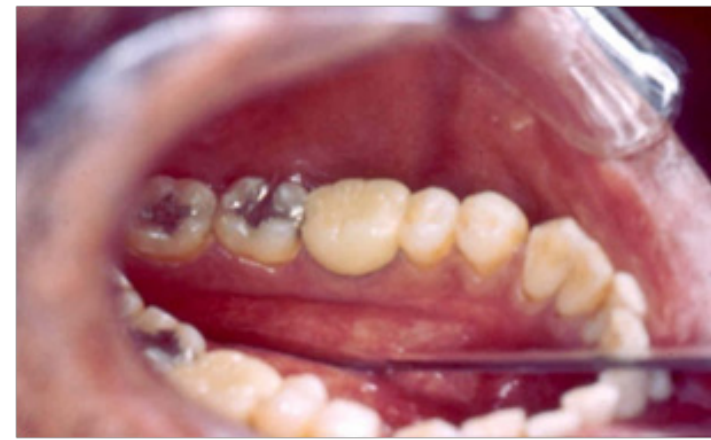

Figure 13 Porcelain fused to metal crown cemented on tooth \#36.

\section{Discussion}

There are many methods, of constructing post and cores for posterior teeth, reported in the literature ${ }^{18-22}$. These methods include using prefabricated post with core build up or cast post and core. The procedures for prefabricated posts are simpler but their retention is inferior to cast posts if elliptical or extremely flared canals exist. The indirect cast post and core technique is still a popular method of fabricating post and core pattern for multi-rooted teeth with non parallel canals, but it has many drawbacks that may affect the accuracy and retention of the post. Success of the indirect method depends on the accuracy of the impression replicating the post whole space. Impression material can be injected into post whole space and distributed by a spiral paste filler to capture the internal canal morphology. ${ }^{23}$ Therefore in the indirect method many dimensional changes takes place during cast post fabrication due to impression and wax pattern materials. 
Although the conventional direct pattern technique allows more accurate registration of one canal morphology in multi rooted teeth that may lead to a better fit of cast post which in turn is expected to improve retention and stability of the final restoration, it is not without drawbacks. One drawback is related to using potentially corrodible dissimilar metals for post and core. Many researchers concluded that there is a correlation between root fracture and corrosion of the base metal prefabricated post and cast core systems restoring them..$^{5-8}$ Another drawback results from casting a core onto a prefabricated post system is that the casting process may unfavorably affect the physical properties of wrought metal posts. The preheating temperature of the investment mold may lead to recrystalization of the wrought metal post. ${ }^{9}$

The present procedures allowed the prosthodontist to fabricate direct cast post and core for multi-rooted teeth with non parallel canals and at the same time eliminate the problems associated with the traditional direct pattern technique. This is because the pattern for posts and core sections are cast from the same alloy; hence the post core system is not susceptible to electrolytic corrosion.

\section{Funding details}

None.

\section{Acknowledgments}

None.

\section{Conflicts of interest}

The authors declare that there is no conflict of interest.

\section{References}

1. Helfer AR, Melnick S, Schilder H. Determination of the moisture content of vital and pulpless teeth. Oral Surg Oral Med Oral Pathol. 1972;34(4): 661-670.

2. Stephen FR, Martin FL, Fujimoto J. Contemporary fixed prosthodontics. 4th ed. Mosby: USA; 2006. $1152 \mathrm{p}$.

3. Morgano SM, Milot P. Clinical success of cast metal posts and cores. $J$ Prosthet Dent. 1993;70(1):11-16.

4. Lu LW, Meng GW, Liu ZH. Finite element analysis of multi-piece postcrown restoration using different types of adhesives. Int J Oral Sci. 2013;5(3):162-166.

5. Rud J, Omnell KA. Root fracture due to corrosion. Diagnostic aspects. Scand J Dent Res. 1970;78(5):397-403.
6. Angmar-Mansson B, Omnell KA, Rud J. Root fracture due to corrosion. 1. Metallurgical aspects. Odontol Revy. 1969;20(3):245-265.

7. Silness J, Gustavsen F, Hunsbeth J. Distribution of corrosion products in teeth restored with metal crowns retained by stainless steel posts. Acta Odontol Scand. 1979;37(6):317-321.

8. Milot P, Stein RS. Root fracture in endodontically treated teeth related to post selection and crown design. J Prosthet Dent. 1992;68(3):428-435.

9. Kwan EH, Harrington GW. The effect of immediate post preparation on apical seal. J Endod. 1981;7(7):325-329.

10. Mattison GD, Delivanis PD, Thacker RW Jr, et al. Effect of post preparation on the apical seal. J Prosthet Dent. 1984;51(6):785-789.

11. Brunell G. Casting and microstructure of post and core at different mold temperatures. Acta Odontol Scand. 1982;40(4):241-246.

12. Coleman AJ, Urquiola J. An injection technique for generating direct resin post and core patterns. Quintessence Int. 1996;27(11):749-752.

13. Awad MA, Abdulghaffar HS. Custom-made post and core - part I: technique to fabricate direct custom-made post with resin pattern. J Dent Health Oral Disord Ther. 2014;1(3):00013.

14. Awad MA. Custom-made post and core - part ii: fabrication of direct resin core using special mold. J Dent Health Oral Disord Ther. 2014;1(3):00014.

15. Ingle JI, Bakland LK. Endodontics: Restoration of endodontically treated teeth. 5th ed. -London: BC Decker Inc Hamilton; 2002.

16. Waldmeier MD, Grasso JE. Light-cured resin for post patterns. J Prosthet Dent. 1992;68(3):412-415.

17. Rosenstiel SF, Land MF, Holloway JA. Custom-cast post fabrication with thermoplastic material. J Prosthet Dent. 1997;77(2):209-211.

18. Baraban DG. A simplified method for making post and cores. J Prosthet Dent. 1970;24(3):287-297.

19. Hudis SI, Goldstein GR. Restoration of endodontically treated teeth: a review of the literature. J Prosthet Dent. 1986;55(1):33-38.

20. Abou-Rass M. Post and core restoration of endodontically treated teeth. Curr Opin Dent. 1992;2:99-107.

21. Schneider RL. A one-appointment procedure for cast post and core restorations. J Prosthet Dent. 1994;71(4):420-422.

22. Morgano SM, Hashem AF, Fotoohi K, et al. A nationwide survey of contemporary philosophies and techniques of restoring endodontically treated teeth. J Prosthet Dent. 1994;72(3):259-267.

23. Sall HD. Restorative techniques for endodontically treated teeth. Dent Surv. 1977;53:45. 